several authorities and institutions that are already active. Appended to the report, moreover, are notes on relevant activities of the National Foundation for Educational Research and the British Association of Commercial and Industrial Education, details of projects already in progress in the London colleges, of the two educational research projects in the Department of Mathematics at the Hatfield College of Technology and of the Nuffield research projects at the Birmingham College of Advanced Technology and at Brunel College.

Although the working party does not lose sight of its main concern-the technical colleges-this general survey is of considerably wider interest and the comments made are probably valid over a fairly wide field of secondary and of higher education. More research is obviously being carried out into technical education than is generally realized. However, the research position is scrappy and disjointed, and the working party believes that the present investment rate is ahead of intelligent application. In particular, besides greater availability of statistics, in the institutional field the clearing services need overhauling to facilitate awareness of what is happening in cognate fields. The working party found great difficulty in discovering the annual investment in the development of research into technical education, but if the planning of research into specialized training within industry is to be absorbed into the prime costs of industry and marketing, i.t suggests that assistance is needed in four ways.

First, established posts are necessary in the centres of higher education in the faculties of arts, education or applied science. Secondly, research units need to be established in universities, colleges of advanced technology, and other institutions, with an independent budget, and headed by specialists who may or may not be members of the academic staff. Thirdly, there is room for specific enquiries in any establishment, industrial or academic, with the use of a research studentship or ad hoc grant. Fourthly, development might be promoted within the National Foundation for Educational Research of the existing division concerned with research and information on technical education.

All this needs manpower and suitable recruitment, and the spread of incentives are at the heart of the whole problem of launching large-scale projects into new territory. The working party particularly stresses the need for more specialized workers in educational psychology, statistical methods, and the design of educational experiments, economic analysis, and sociology. It lists the topies for research in five broad groups, but makes no attempt to indicate a desirable priority. The groups cover entry to technical education and training, mothods of teaching and training; relation between technical education and industrial and commercial training; problems of a broad scope, such as forecasting needs for technical personnel, aspects of public examinations, economics of the technical education; and comparative studies of technical education.

Even the titles of the broad groups of projects listed in this report indicate the implication of such research in other fields of education. The working party considers the question whether the developing situation calls for national supervision by some body after the style of the Medical Research Council. It is firmly of the opinion that, whether or not such surveillance is desirable, existing organizations must accept the need for close co-operation and the pooling of information and must agree on some form of clearing-house facilities. The Ministry of Education and the Scottish Education Department, the Ministry of Labour, the National Foundation for Educational Research, the Scottish Council for Research in Education, the National Advisory Council on Education for Industry and Commerce, the British Association for Commercial and Industrial Education are all concerned in one way or another, and the universities, local education authorities and organizations of teachers also have interests to develop. All these in coming together should attempt some more formal and structural form of co-ordination.

The working party considers that the initiative in securing closer co-operation should be taken by the Government, and points out that the case for creating a national council or grants committee, with powers to handle funds, to consider the direction of policy and to report to the Privy Council through a Minister, would be stronger if considerable sums from the national exchequer became available for disbursal among institutions engaged with research projects. Such a step would not, however, remove the need for much closer co-operation generally; it reiterates that the lead in developing new work must be taken by the National Foundation, the universities, the technical teacher training colleges, industrial firms and associations, local education authorities, and associations of principals and teachers in technical colleges, regional advisory councils, and the technical colleges and teachers themselves. It sees hopeful signs in the creation of the intelligence and research organization of the Ministry of Education, and the increased support given to the National Foundation for Educational Research. Furthermore, it suggests that the universities through their Departments of Education may be able, in the next quinquennium, to direct more of their resources into problems of technical education and to encourage postgraduate research in this field. This is important in view of the great need for research workers, and the working party suggests that conditions for the award of academic qualifications as a result of educational research should be broadened to give postgraduate workers in this field an incentive comparable with that of postgraduate workers in scientific and technical research.

\title{
MODIFICATION OF THE WEATHER
}

\begin{abstract}
$\mathrm{T}$ HE great economic potential of successful weather control led the United States Congress in 1958 to ask the National Science Foundation to launch a full-scale investigation of this exciting field of modern meteorology. Within the Foundation, a Weather Modification Research Programme has been developed as an integral part of the more inclusive Programme on Atmospheric Sciences, which required funds amounting to $6,615,000$ dollars during the fiscal year ending June, 1962. Of this sum, $1,340,000$ dollars were set aside to support weather modification research under a system of grants and contracts from the Foundation to research groups at university, Government and other laboratories.

The one major technique in use for weather modifica. tion is only fifteen years old. This is 'cloud seeding', that
\end{abstract}

is, the introduction, into a cloud, of material calculated to have an effect on the constituent cloud particles. Certain clouds and types of fog can be modified; and, under certain conditions, rainfall can be somewhat augmented and hail discouraged. The possibilities merit further careful investigation.

A summary of progress made in the United States National Weather Modification Programme up to 1962 appears in a report1 issued by $\mathrm{L}$. J. Haworth, director of the National Science Foundation. Work has been concentrated on basic studies into the nature of cloud phenomena, on the study of known cloud-seeding methods, and on the investigation of other methods of local modification of clouds. The last-mentioned investigation includes methods of changing ascending or descending air currents, or of 
changing the electrical field of the cloud by, for example, hanging miles of electrified wire across canyons in North Mexico. The Foundation also sponsors investigations in atmospheric dynamics and the general circulation, and these may make significant contributions to the investigation of weather modification over large regions; and on the large scale may eventually determine what kinds of man-made influences can affect large weather patterns, and climate. Large-scale weather modification is, by nature, international in scope, and co-operation and coordination is essential between some twenty nations at present making research efforts in weather modification.

The report also contains the results of a Rand Corporation study group ${ }^{2}$, briefed by the Foundation to analyse past and present attempts at modifying weather and to consider suggestions for achieving weather control; the Rand group emphasized the importance of co-ordination of theory with mathematical models of the atmosphere for the electronic computer, with laboratory models and other laboratory studies, as well as with field observations. Modification may be possible through an understanding of the physical processes involved within a cloud; or of the air currents associated with it; or of the major synoptic weather systems and the general circulation. Various associated investigations should be encouraged, for example, palæoclimatology may be helpful in revealing causes of the great climatic changes of the past. The various effects of man-made atmospheric pollution should be studied, for example, carbon dioxide, and the pollution of the upper atmosphere by space vehicles and rockets.

Theoretical studies are aided by large electronic computers for solving the equations of motion of simplified models of the atmosphere. The use of such models permits the research worker to test the effect of suggested methods of weather modification, for example, the effect of damming the Bering Strait; or of removing ice from the Arctic Sea; of controlling evaporation over the ocean by covering the surface with a chemical film; or of changing the radiation balance over snow surface by a coating of carbon black; or of finding the most favourable circumstances in which a small modification might act as a 'trigger mechanism' to set off a larger modification. Calculations may also be made on small-scale diurnal phenomena, for example, the behaviour of fog and stratus cloud at a coast line. Even smaller scale atmospheric motions within clouds may be studied, for example, to show collision frequencies of cloud droplets and possible changes due to modified electric fields.

Besides including further computer studies, the future plans of the Foundation again involve such projects as cloud-seeding research and the effects of 'seeding' on hurricanes, research on cloud electrification and research on the control of the hydrological cycle through control of evaporation.

Space technology and radiation studies may even lead to control of the radiation balance by altering the composition of the upper levels of the atmosphere, or by introducing artificial cloud layers in suitablo places. The report concludes that the time for rapid progress appears to be at hand with a variety of new theoretical and prac. tical tools, provided that the project continues to attract well-trained and talented man-power. W. GARRIOCK

1 National Science Foundation, Washington. Weather Modification: Fourth Annual Report for Fiscal Year ended June 30, 1962. Pp. v $+84+7$ plates. (Washington, D.C.: Government Printing Office, 1963.) 50 cents. ${ }^{2}$ Greenfield, S. M., et al., A Rationale for Weather Control Research, Trans. Amer. Geophys. Union, 43, No. 4, 469 (December 1962).

\title{
A WORKING MODEL OF THE MECHANICAL ESCAPEMENT IN SU SUNG'S ASTRONOMICAL CLOCK TOWER
}

\author{
By Prof. AUbrey F. BURSTALL, W. E. LANSDALE and P. ELLIOTT \\ Department of Mechanical and Marine Engineering, University of Newcastle upon Tyne
}

\begin{abstract}
N 1960, Drs. Needham, Wang Ling and Price published a detailed description of the mechanism in the Chinese astronomical clock tower built for the Emperor by Su Sung in A.D. 1092 (ref. 1), in which the mechanical power for driving the mechanism was provided by a large wheel eleven feet in diameter mounted with its axis horizontal, the wheel carrying thirty-six scoops equally spaced around its circumference. The wheel moved intermittently as the result of water flowing into the scoops in turn, the weight of water in a full scoop being sufficient to tilt a weighted lever obstructing the movement of the wheel, and the water poured out of each scoop after it had passed the weighted lever. The wheel was brought to rest after the passage of each scoop by stops worked by latches while the wheel was in motion. The authors claimed that the apparatus was of great importance to the history of mechanical clockwork since it provided a 'missing link' between the water clocks and clepsydra of antiquity and the first mechanical escapements developed in the West during the Middle Ages. They suggested: "that the whole design is reminiscent of the anchor escapement of the late seventeenth century, since the driving wheol is a scape wheel and the pallets are inserted alternately at two points on its circumference separated by $90^{\circ}$ or less ..." In a footnote on the same page they observe, "the more subtle aspects of Su Sung's mechanism will not reveal themselves until a working model has been constructed. We may hope that such a task will be undertaken ..."

The prosent authors took up this challenge and have now produced a working model (their Mark III model:
\end{abstract}

the first two models, though they operated successfully, did not meet all the requirements specified in Heavenly Clockwork) which appears to meet the requirements specified in the text and, furthermore, incorporates a component essential to the operation of the mechanism and described by the translators simply as "some kind of star-shaped gadget", the function of which they were unable to guess. We have named it "an interrupter cam".

Our own reading of the text of Heavenly Clockwork together with experiments we have made with two earlier models lead us to believe that Su Sung's escapement was composed of eight distinct elements each one of which was essential for its operation.

They are shown diagrammatically in Fig. 1 and were: (A) The 'scape' wheel carrying thirty-six scoops equally spaced around the periphery. As the wheel turned it was arrested as each scoop reached the horizontal diameter where it was filled with water until the wheel moved on for the next scoop to be filled after tilting the woighted lever $(B)$. Each scoop carried a projecting pin at one side for operating the escape latch $(C)$. $(B)$ A weighted lever hinged near the centre provided with a counter poise at one end and a forked end for stopping the scoops at the other. A pin between the fork of this lever operated the interrupter cam $(G)$ just before the wheol was stopped by the buffer and caused to recoil. (C) An escape latch connected by the chain $(D)$ to the overhead stopping lever $(E)$ which carried a buffer stop at one end. This buffer stop normally rested between two adjacent pins at the 